\title{
Efeito da raça, dieta, época e ordem de parição na concentração de imunoglobulina $\mathrm{G}$ no colostro de suínos ${ }^{(1)}$
}

\author{
Raul Machado Neto(2), Irineu Umberto Packer ${ }^{(2)}$, José Fernando Menten ${ }^{(2)}$ e Abel Lavorenti(2)
}

\begin{abstract}
Resumo - Este trabalho teve por objetivo estudar os efeitos da raça, dieta, época do ano e ordem de parição na concentração de imunoglobulina $\mathrm{G}(\mathrm{IgG})$ no colostro de porcas. A concentração de IgG foi determinada no colostro de 60 porcas, 33 da raça Large White e 27 da raça Landrace, submetidas a dietas contendo $0 \%, 7 \%, 14 \%$ e $21 \%$ de levedura seca (LS). A levedura seca de destilaria de álcool de cana-de-açúcar (Saccharomyces cerevisiae) substituiu parte do milho e do farelo de soja da ração mantendo o nível de $14 \%$ de proteína bruta. Não foi verificado efeito significativo $(\mathrm{P}>0,05)$ de raça e da dieta sobre a concentração de IgG do colostro. Os valores mais elevados de IgG foram observados no colostro de porcas que pariram entre maio e outubro $(\mathrm{P}<0,05)$. Foram obtidos efeitos quadrático $(\mathrm{P}<0,10)$ e cúbico $(\mathrm{P}<0,01)$ da ordem de parição sobre a concentração de IgG. As fêmeas de primeira cria apresentaram o menor valor $(\mathrm{P}<0,05)$ de concentração de $\operatorname{IgG}(49,98 \pm 7,9 \mathrm{mg} / \mathrm{mL})$ em relação às fêmeas de segunda $(92,70 \pm 5,9 \mathrm{mg} / \mathrm{mL})$, terceira $(70,72 \pm 5,6 \mathrm{mg} / \mathrm{mL})$ e quarta crias $(85,56 \pm 9,0 \mathrm{mg} / \mathrm{mL})$, evidenciando que animais com maior experiência imunológica apresentam maior concentração de imunoglobulina no colostro.
\end{abstract}

Termos para indexação: imunidade passiva, porcas, anticorpos, fatores imunológicos.

\section{Effect of breed, diet, period and lactation numbers on immunoglobulin $\mathbf{G}$ concentration in swine colostrum}

\begin{abstract}
The objective of the present study was to determine the effects of breed, diet, period of the year and lactation numbers on the concentration of immunoglobulin $\mathrm{G}(\mathrm{IgG})$ in sows colostrum. IgG concentration was determined in colostrum of 60 sows (33 Large White and 27 Landrace) submitted to four different diets with $0 \%, 7 \%, 14 \%$ and $21 \%$ of dried yeast. Dried yeast from alcohol of sugar cane industry (Saccharomyces cerevisiae) was used as substitute for corn and soybean mill keeping the level of crude protein at $14 \%$. IgG concentration in the colostrum was not affected by breed and diet. Higher concentration of IgG was found in colostrum of sows farrowing occurred between May and October $(\mathrm{P}<0.05)$. Quadratic $(\mathrm{P}<0.10)$ and cubic $(\mathrm{P}<0.01)$ effects of parturition order on IgG concentration were detected. Females from first parturition had lower concentration $(\mathrm{P}<0.05)$ of $\operatorname{IgG}$ $(49.98 \pm 7.9 \mathrm{mg} / \mathrm{mL})$ compared to females from second $(92.70 \pm 5.9 \mathrm{mg} / \mathrm{mL})$, third $(70.72 \pm 5.6 \mathrm{mg} / \mathrm{mL})$ and fourth $(85.56 \pm 9.0 \mathrm{mg} / \mathrm{mL})$ parturition, demonstrating that animals with more immunological experience have higher concentrations of $\mathrm{IgG}$ in the colostrum.
\end{abstract}

Index terms: passive immunity, sows, antibodies, immunological factors.

\section{Introdução}

A placenta do tipo epiteliocorial, encontrada nos suínos, impede a transferência de imunoglobulinas maternas para o feto em desenvolvimento.

(1) Aceito para publicação em 20 de novembro de 2000 .

(2) Escola Superior de Agricultura Luiz de Queiroz, Dep. de Produção Animal, Caixa Postal 9, CEP 13418-900 Piracicaba, SP E-mail: rmachado@carpa.ciagri.usp.br,

iupacker@carpa.ciagri.usp.br,.jfmmente@carpa.ciagri.usp.br
Assim, leitões ao nascer são praticamente agamaglobulinêmicos, dependendo inteiramente do colostro para aquisição das imunoglobulinas que irão conferir a proteção inicial, necessária para sua sobrevivência (Brambell, 1958).

Para a maior parte dos animais domésticos, incluindo os suínos, a imunoglobulina $\mathrm{G}$, que se apresenta com concentração máxima no colostro por ocasião do parto, constitui a mais importante classe de anticorpos. Após o parto, a concentração de imunoglobulinas na secreção láctea decresce a cada 
aleitamento sucessivo, coincidindo com o período de absorção dessas macromoléculas pelo intestino dos animais recém-nascidos, que também é máxima nas primeiras horas de vida e diminui rapidamente, para desaparecer quase completamente em dois ou três dias (Lecce \& Matrone, 1960; Lecce, 1971; Menge \& Frobish, 1976; Bourne et al., 1978; Machado Neto et al., 1987; Drew et al., 1990; Lanza et al., 1995). Bourne (1969) calculou uma redução da ordem de $25 \%$ na concentração de IgG no colostro das porcas nas dez primeiras horas após o parto.

A importância de estudar os fatores que afetam a concentração de imunoglobulinas do colostro de suínos é justificada plenamente pela função que ele desempenha na proteção inicial dos leitões recémnascidos (Lecce \& Matrone, 1960; Heugten et al., 1994; Stahly, 1994; Mahan, 1998).

O presente trabalho teve por objetivo estudar os efeitos da raça, dieta, época do ano e ordem de parição sobre a concentração de imunoglobulina $G$ no colostro de porcas.

\section{Material e Métodos}

O experimento foi conduzido na Escola Superior de Agricultura Luiz de Queiroz, da Universidade de São Paulo, fase de campo realizada entre 1981 e 1983, nas instalações do Departamento de Produção Animal, Campus Luiz de Queiroz, Piracicaba, São Paulo.

Foram analisadas amostras de colostro proveniente de 60 porcas (33 da raça Large White e 27 da raça Landrace) submetidas a quatro diferentes dietas contendo níveis crescentes de levedura seca (LS): $0 \%, 7 \%, 14 \%$ e $21 \%$. A levedura seca de destilaria de álcool de cana-de-açúcar (Saccharomyces cerevisiae) substituiu parte do milho e do farelo de soja da ração, mantendo-se o nível de $14 \%$ de proteína bruta. As rações experimentais, formuladas de acordo com o National Research Council (1979), foram fornecidas durante até quatro ciclos reprodutivos. $\mathrm{Na} \mathrm{Ta}-$ bela 1 é apresentada a composição das rações experimentais.

As amostras de colostro para análise constituíram um homogeneizado de secreções de tetas da região posterior, obtidas no momento do parto.

A determinação de imunoglobulina $\mathrm{G}$ (IgG) foi feita pelo método de imunodifusão radial, descrito por Mancini et al. (1965), modificado por Fleenor \& Stott (1981), para quantificação em colostro. Foram utilizados os produtos IgG padrão e anti-IgG, produzidos comercialmente (Sigma
Chemical Company - USA), em placas de agarose com tampão Tris-HCl, pH 8,0. Além das curvas padrão, desenvolvidas em placas próprias, todas as placas com amostras continham duas concentrações-padrão para controle da variação entre placas. As duplicatas com variação acima de $5 \%$ foram repetidas.

Os dados foram analisados de acordo com um modelo envolvendo os efeitos raça, dieta, época e ordem de parto, conforme Harvey (1979). Os efeitos de ordem de parto e do nível de levedura seca na ração foram decompostos em componentes linear, quadrático e cúbico, enquanto a comparação das médias de época foi feita pelo teste de Tukey.

\section{Resultados e Discussão}

Não houve efeito significativo $(\mathrm{P}>0,05)$ de raça e dieta sobre a concentração de $\mathrm{IgG}$ do colostro. A substituição da fonte protéica não determinou diferenças significativas, e tampouco, tendências linear ou quadrática relacionadas aos níveis de substituição da soja pela levedura seca (Tabelas 1 e 2), embora sejam relatados na literatura efeitos desses dois fatores. Inoue et al. (1980) encontraram uma concentração de IgG inferior no colostro de porcas Hampshire, Large White e Landrace x Large White, em comparação com colostro de Landrace, Landrace x Hampshire e de outros cruzamentos com Landrace. Por outro lado, Bowland et al. (1949) não encontraram diferença na concentração protéica de

Tabela 1. Composição porcentual das rações experimentais em dietas de porcas submetidas a níveis crescentes de levedura seca.

\begin{tabular}{lrrrr}
\hline Componente & \multicolumn{4}{c}{ Levedura seca (\%) } \\
\cline { 2 - 5 } & 0,00 & 7,00 & 14,00 & 21,00 \\
\hline Milho moído & 78,10 & 75,50 & 72,80 & 70,10 \\
Farelo de soja & 12,70 & 8,60 & 4,50 & 0,40 \\
Farelo de trigo & 5,00 & 5,00 & 5,00 & 5,00 \\
Fosfato bicálcico & 3,00 & 2,70 & 2,50 & 2,30 \\
Sal iodado & 0,50 & 0,50 & 0,50 & 0,50 \\
Mistura de vit. e minerais & 0,70 & 0,70 & 0,70 & 0,70 \\
Proteína bruta & 14,02 & 14,02 & 14,00 & 14,00 \\
Lisina & 0,59 & 0,59 & 0,59 & 0,60 \\
Metionina & 0,26 & 0,25 & 0,25 & 0,23 \\
Fibra bruta & 2,77 & 2,56 & 2,35 & 2,14 \\
Cálcio & 0,79 & 0,79 & 0,82 & 0,85 \\
Fósforo disponível & 0,66 & 0,63 & 0,63 & 0,62 \\
Energia digest. (kcal/kg) & 3331 & 3306 & 3277 & 3248 \\
Energia metabol. (kcal/kg) & 3136 & 3109 & 3079 & 3047 \\
\hline
\end{tabular}


colostro oriundo de porcas Chester White comparadas com Poland China. Em bovinos, o efeito de raça sobre a concentração de IgG no colostro foi verificado em vários estudos (Muller \& Ellinger, 1981; Norman et al., 1981; Vann et al., 1995). Com relação ao efeito de dieta sobre a concentração de anticorpos no colostro, os resultados não se mostram conclusivos. Os autores apontam o manejo como um importante fator de influência (Bowland et al., 1949; Logan, 1977; Inoue et al., 1980; Morin et al., 1997). Valores mais elevados de $\operatorname{IgG}(\mathrm{P}<0,05)$ foram verificados quando os partos ocorreram entre maio e outubro (Tabela 2). Inoue et al. (1980), trabalhando com suínos, também encontraram valores mais elevados em colostro de partos ocorridos na primavera, e os valores mais baixos, no verão. A interpretação desses resultados torna-se complexa em face das variáveis relacionadas com as condições de manejo do parto. No entanto, este efeito é minimizado nas condições comerciais, pois na maior parte das operações a temperatura é mantida parcialmente sob controle.

Foram verificados efeitos quadrático $(\mathrm{P}<0,10) \mathrm{e}$ cúbico $(\mathrm{P}<0,01)$ da ordem de parição sobre a con-

Tabela 2. Concentrações de imunoglobulina G (IgG) no colostro de porcas das raças Large White e Landrace, alimentadas com dietas contendo levedura seca, em diferentes épocas e ordem de parto ${ }^{(1)}$.

\begin{tabular}{|c|c|c|c|}
\hline Fator & $\begin{array}{c}\text { Número de } \\
\text { porcas }\end{array}$ & $\mathrm{IgG}(\mathrm{mg} / \mathrm{mL})$ & $\begin{array}{c}\text { Erro-padrão } \\
\text { da média }\end{array}$ \\
\hline \multicolumn{4}{|l|}{ Raça } \\
\hline Large White & 33 & $73,85 \mathrm{a}$ & 3,4 \\
\hline Landrace & 27 & $75,64 \mathrm{a}$ & 3,7 \\
\hline \multicolumn{4}{|l|}{ Levedura $(\%)^{(2)}$} \\
\hline 0 & 11 & 73,17 & 5,6 \\
\hline 7 & 20 & 76,94 & 4,1 \\
\hline 14 & 10 & 73,78 & 5,4 \\
\hline 21 & 19 & 75,08 & 4,4 \\
\hline \multicolumn{4}{|l|}{ Época (meses) } \\
\hline $\mathrm{J}-\mathrm{F}$ & 12 & $58,10 \mathrm{~b}$ & 6,0 \\
\hline M-A & 13 & $59,77 \mathrm{~b}$ & 7,2 \\
\hline M-J & 4 & $81,29 \mathrm{a}$ & 9,8 \\
\hline $\mathrm{J}-\mathrm{A}$ & 15 & $91,48 \mathrm{a}$ & 5,7 \\
\hline $\mathrm{S}-\mathrm{O}$ & 11 & $86,54 \mathrm{a}$ & 9,1 \\
\hline N-D & 5 & $71,28 \mathrm{ab}$ & 7,9 \\
\hline \multicolumn{4}{|l|}{ Ordem de parto $^{(3)}$} \\
\hline 1 & 17 & 49,98 & 7,9 \\
\hline 2 & 23 & 92,70 & 5,9 \\
\hline 3 & 15 & 70,72 & 5,6 \\
\hline 4 & 5 & 85,56 & 9,0 \\
\hline
\end{tabular}

centração de IgG, e observou-se aumento dessa variável da primeira cria para as demais (Tabela 2) e posterior redução. Esta condição de porcas aumentarem a concentração de IgG com a idade, também foi encontrada por Inoue et al. (1980) e Klobasa \& Butler (1987), os quais verificaram elevações significativas na concentração de IgG do colostro a partir da terceira e quarta lactações, respectivamente. No entanto, em outro estudo de Klobasa et al. (1987), o efeito de número de parições não foi verificado. Em bovinos, vários são os trabalhos que relatam uma relação positiva entre o número de parições e a concentração de IgG no colostro (Oyeniyi \& Hunter, 1978; Muller \& Ellinger, 1981; Norman et al., 1981; Donovan et al., 1986). Esse efeito pode ser explicado pelo desenvolvimento do sistema imunológico que ocorre com a idade, graças ao maior número de situações antígeno-anticorpo acumuladas ao longo do tempo; esta justificativa também foi apresentada por Donovan et al. (1986), ao discutir resultados semelhantes obtidos com bovinos.

Os valores de imunoglobulinas no colostro, em torno de $50 \mathrm{mg} / \mathrm{mL}$, encontrados no presente trabalho, de acordo com o proposto por Fleenor \& Stott (1980) para bovinos, seriam classificados como colostro de qualidade moderada superior à excelente inferior.

\section{Conclusões}

1. A raça e a dieta não influem na concentração de IgG do colostro.

2. A concentração de IgG do colostro é influenciada pela ordem de parição e pela época do parto.

3. As fêmeas de primeira cria apresentam menor valor de concentração de IgG no colostro em relação às fêmeas de segunda, terceira e quarta crias.

\section{Referências}

BOURNE, F. J. Studies on colostral and milk proteins in the sows: I. The transmission of mammary secretion from colostrum to milk with natural suckling. Animal Production, Pencaitland, v. 11, p. 337-343, 1969.

BOURNE, F. J.; NEWBY, T. J.; EVANS, P.; MORGAN, $\mathrm{K}$. The immune requirements of the newborn pig and calf. Annales de Recherches Veterinaires, Paris, v. 9, n. 2, p. 239-244, 1978.

Pesq. agropec. bras., Brasília, v. 36, n. 10, p. 1295-1299, out. 2001 
BOWLAND, J. P.; GRUMMER, R. H.; PHILLIPS, P. H.; BOHSTEDT, G. The effect of the plane of nutrition on the composition of sows colostrum and milk. Journal of Animal Science, Champaign, v. 8, n. 2, p. 199-206, 1949.

BRAMBELL, F. W. R. The passive immunity of the young mammal. Biological Review, Ricany, v. 33, n. 4, p. 488531, Nov. 1958.

DONOVAN, G. A.; BADINGA, L.; COLLIER, R. J.; WILCOX, C. J.; BRAUN, R. K. Factors influencing passive transfer in dairy calves. Journal of Dairy Science, Champaign, v. 69, n. 3, p. 754-759, Mar. 1986.

DREW, M. D.; BEVANDICK, I. M.; OWEN, B. D. Artificial rearing of colostrum-deprived piglets using iron chelators: The effects of oral administration of EDDHA with and without bovine or porcine immunoglobulins on piglet performance and iron metabolism. Canadian Journal of Animal Science, Ottawa, v. 70, n. 2, p. 655 666, June 1990.

FLEENOR, W. A.; STOTT, G. H. Hydrometer test for estimation of immunoglobulin concentration in bovine colostrum. Journal of Dairy Science, Champaign, v. 63, n. 6, p. 973-977, June 1980.

FLEENOR, W. A.; STOTT, G. H. Single radial immunodiffusion analysis for quantitation of colostral immunoglobulin concentration. Journal of Dairy Science, Champaign, v. 64, n. 5, p. 740-747, May 1981.

HARVEY, W. R. Least-squares analysis of data. Columbus: USDA, 1979. $157 \mathrm{p}$.

HEUGTEN, E. van; SPEARS, J. W.; COFFEY, M. T. The effect of dietary protein on performance and immune response in wealing pigs subjected to an inflammatory challenge. Journal of Animal Science, Champaign, v. 72, n. 10, p. 2661-2669, Oct. 1994.

INOUE, T.; KITANO, K.; INOUE, K. Possible factors influencing the immunoglobulin $\mathrm{G}$ concentration in swine colostrum. American Journal of Veterinary Research, Schaumburg, v. 41, n. 7, p. 1134-1136, July 1980.

KLOBASA, F.; BUTLER, J. E. Absolute and relative concentrations of immunoglobulins $\mathrm{G}, \mathrm{M}$, and $\mathrm{A}$, and albumin in the lacteal secretion of sows of different lactation numbers. American Journal of Veterinary Research, Schaumburg, v. 48, n. 2, p. 176-182, Feb. 1987.

KLOBASA, F.; WERHAHM, E.; BUTLER, J. E. Composition of sow milk during lactation. Journal of Animal Science, Champaign, v. 64, n. 5, p. 1458-1466, May 1987.

LANZA, I.; SHOUP, D. I.; SAIF, L. J. Lactogenic immunity and milk antibody isotypes to transmissible gastroenteritis virus in sows exposed to porcine respiratory coronavirus during pregnancy. American Journal of Veterinary Research, Schaumburg, v. 56, n. 6, p. 739-748, June 1995.

LECCE, J. G. Rearing neonatal piglets of low birth weight with on automatic feeding device. Journal of Animal Science, Champaign, v. 33, n. 1, p. 47-51, 1971.

LECCE, J. G.; MATRONE, G. Porcine neonatal nutrition: The effect of diet on blood serum proteins and performance of the baby pig. Journal of Nutrition, Bethesda, v. 70, n. 1, p. $13-20,1960$

LOGAN, E. F. The influence of husbandry on colostrum yield and immunoglobulin concentration in beef cows. British Veterinary Journal, London, v. 133, n. 2, p. 120125, 1977.

MACHADO NETO, R.; GRAVES, C. N.; CURTIS, S. E. Immunoglobulins in piglets from sows heat-stressed prepartum. Journal of Animal Science, Champaign, v. 65, n. 2, p. 445-455, Aug. 1987.

MAHAN, D. C. Relationship of gestation protein and feed intake level over a five-parity period using a highproducing sow genotype. Journal of Animal Science, Champaign, v. 76, n. 2, p. 533-541, Feb. 1998.

MANCINI, G.; CARBONARA, A. O.; HEREMANS, J. F. Immunochemical quantitation of antigenous by single radial immunodiffusion. Immunochemistry, Oxford, v. 2, n. 3, p. 235-254, Sep. 1965.

MENGE, H.; FROBISH, L. T. Nutritional studies with early weaned neonatal pig. Journal of Animal Science, Champaign, v. 42, n. 1, p. 99-105, 1976.

MORIN, D. E.; McCOY, G. C.; HURLEY, W. L. Effects of quality, quantity, and timing of colostrum feeding and addition of a dried colostrum supplement on immunogloblin $G_{1}$ absorption in Holstein bull calves. Journal of Dairy Science, Champaign, v. 80, n. 4, p. 747 753, Apr. 1997.

MUlleR, L. D.; ELlingeR, D. E. Colostral immunoglobulin concentration among breeds of dairy cattle. Journal of Dairy Science, Champaign, v. 64, n. 8, p. 1727-1730, Aug. 1981. 
NATIONAL RESEARCH COUNCIL (Washington, Estados Unidos). Nutrient requirements of swine. 8. rev. ed. Washington: National Academy of Sciences, 1979. 52 p. (Nutrient requirements of domestic animals, 2).

NORMAN, L. M.; HOHENBOKEN, W. D.; KELLEY, $\mathrm{K}$. W. Genetic differences in concentration of immunoglobulins $\mathrm{G}_{1}$ and $\mathrm{M}$ in serum and colostrum of cows and in serum of neonatal calves. Journal of Animal Science, Champaign, v. 53, n. 6, p. 1465-1472, June 1981.

OYENIYI, O. O.; HUNTER, A. G. Colostral constituents including immunoglobulins in the first three milkings postpartum. Journal of Dairy Science, Champaign, v. 61, n. 1, p. 44-48, Jan. 1978.

STAHLY, T. Immune system activation affects pig growth, nutrients needs. Feedstuffs, Minnetonka, v. 24, p. 12-13, Oct. 1994.

VANN, R. C.; HOLLOWAY, J. W.; CARSTENS, G. E.; BOYD, M. E.; RANDEL, R. D. Influence of calf genotype on colostral immunoglobulins in Bos taurus and Bos indicus cows and serum immunoglobulins in their calves. Journal of Animal Science, Champaign, v. 73, n. 10, p. 3044-3050, Oct. 1995. 